\title{
Hyperlipidaemia in children on regular haemodialysis
}

\author{
M. EL-BISHTI, R. COUNAHAN, R. J. JARRETT, L. STIMMLER, V. WASS, AND C. CHANTLER \\ From Evelina Children's Department, Guy's Hospital, London
}

SUMMARY Fasting plasma concentrations of triglycerides (TG), cholesterol, immunoreactive insulin (IRI), and blood glucose were raised in 16 children with chronic renal failure on regular haemodialysis compared with 18 healthy children. In the patients plasma IRI correlated positively with plasma TG, while blood glucose did not correlate with IRI or lipid concentrations. Dietary intake, expressed as percentage of recommended intake for height-age, did not correlate with plasma lipids, but there was a positive correlation between plasma TG and the proportion of calories derived from carbohydrate. The children were not malnourished as evidenced by normal plasma albumin and transferrin concentrations.

The mechanism of the hyperlipidaemia is unclear but it may be related to the glucose intolerance with hyperinsulinaemia which is found in uraemia. In view of the risk of premature atherosclerosis, plasma lipid concentrations should be monitored in children with chronic renal failure and attempts made to ameliorate hyperlipidaemia with appropriate dietary manipulations.

Hyperlipidaemia is a frequent finding in uraemic adults (Bagdade et al., 1968; Gutman et al., 1973; Ibels et al., 1975). Many children with chronic renal failure are now being treated by regular haemodialysis and are often encouraged to take carbohydrate and fat supplements in their diet in an attempt to improve growth. An assessment of plasma lipids, particularly in relation to diet, therefore becomes important for rational management of these children.

We report plasma concentrations of triglycerides (TG) and cholesterol in children on regular haemodialysis with particular reference to diet, nutritional status, plasma concentrations of immunoreactive insulin (IRI), and blood glucose levels.

\section{Patients}

Sixteen children, 9 boys and 7 girls, with a mean age of 14 years (range 11-17 years) were studied. All patients were stable at the time of investigation and had been on dialysis for more than 6 months (range 7 months- 6 years). None had the nephrotic syndrome, clinical or biochemical evidence of diabetes mellitus, or liver disease, or a known family history of hyperlipoproteinaemia. All the children were dialysed overnight at home for 30 hours per week in three sessions, 13 using Meltec Multipoint dialysers, 2 using Watson-Marlow Kiil type dialysers, and 1

Received 25 April 1977 using a Travenol Ultra-Flow dialyser. The dialysate had a dextrose concentration of $200 \mathrm{mg} / 100 \mathrm{ml}$. Apart from strict fluid and some sodium and potassium restriction, they ate a free diet with varying amounts of energy supplements based on a glucose polymer (Caloreen, Milner Scientific and Medical Research Co., Liverpool) and added double-cream (4 kcals $/ \mathrm{ml} ; 17 \mathrm{~kJ} / \mathrm{ml}$ ). Control values were obtained from 18 healthy British children in fasting state, 12 boys and 6 girls with a mean age of $12 \cdot 3$ years (range 10-17) requiring venepuncture for other reasons while inpatients for minor surgery. None had renal disease or systemic illness. They took a normal diet but intakes were not formally assessed. Consent was obtained in writing from the children's parents after full explanation of the procedures to both parents and children and the study was approved by the Medical School Ethical Committee.

\section{Methods}

Clinical. All patients were studied as outpatients at least 28 hours after dialysis and after an overnight fast of more than 12 hours. Blood samples were taken without stasis for the estimation of plasma concentrations of TG, cholesterol, IRI, albumin and transferrin, and blood glucose. The blood was immediately separated and plasma for IRI measurement was frozen at $-20^{\circ} \mathrm{C}$ until assayed. Samples for plasma lipids were kept at $4^{\circ} \mathrm{C}$ and estimations and 32 
serum lipoprotein electrophoresis were carried out on the same day. Diet was assessed by prospective 3-day weighed records. All items of food and fluids taken by the child on three successive days, including one dialysis day, each month were recorded. Nutrient intakes were calculated from the diet records using standard tables (McCance and Widdowson, 1969). For this investigation the intake record closest to the time of study was used and was within 3 weeks of the blood specimens being obtained. The dietary intakes were expressed as a percentage of the recommended intake (\% RI) for the height-age of the child (Department of Health and Social Security, 1969).

Analytical. Plasma TG was measured by the semiautomated fluorimetric method of Cramp and Robertson (1968) and plasma cholesterol by the automated method of Levine and Zak (1964). The double-antibody immunochemical technique was used to measure IRI (Morgan and Lazarow, 1963). Plasma transferrin was determined by a single radial immunodiffusion using Immuno-Plate III (Hyland). Plasma albumin was measured by autoanalyser (bromocresol dye-binding method, Technicon). Lipoprotein electrophoresis was performed on agarose gel. Blood glucose was measured by autoanalyser (ferricyanide method, Technicon).
Statistical. Student's $t$ test was used to compare plasma lipids, IRI, albumin, transferrin, and glucose in patients and controls. The relationship between plasma lipids and nutrition, IRI and TG, were analysed by least squares linear regression.

\section{Results}

Clinical data of the patients are given in Table 1. Table 2 gives the plasma lipids, IRI, albumin, and transferrin concentrations and blood glucose levels in the patients and controls. There were significant increases in both the plasma TG and plasma cholesterol concentrations in the patients compared with controls. No relationship was found between plasma lipid levels and age or sex of the patients or their ideal body weight for height-age. No patient had detectable chylomicrons or a broad beta-band on lipoprotein electrophoresis. Type IV hyperlipoproteinaemia was the predominant finding, occurring in 10 of the children. Four had type IIb and 2 had normal patterns. There was a significant increase in basal IRI and fasting blood glucose in the patients compared with controls. The fasting plasma TG was positively correlated with basal IRI (Fig. 1), but not with fasting blood glucose. IRI and fasting blood glucose were not correlated. Plasma albumin

Table 1 Clinical data of patients

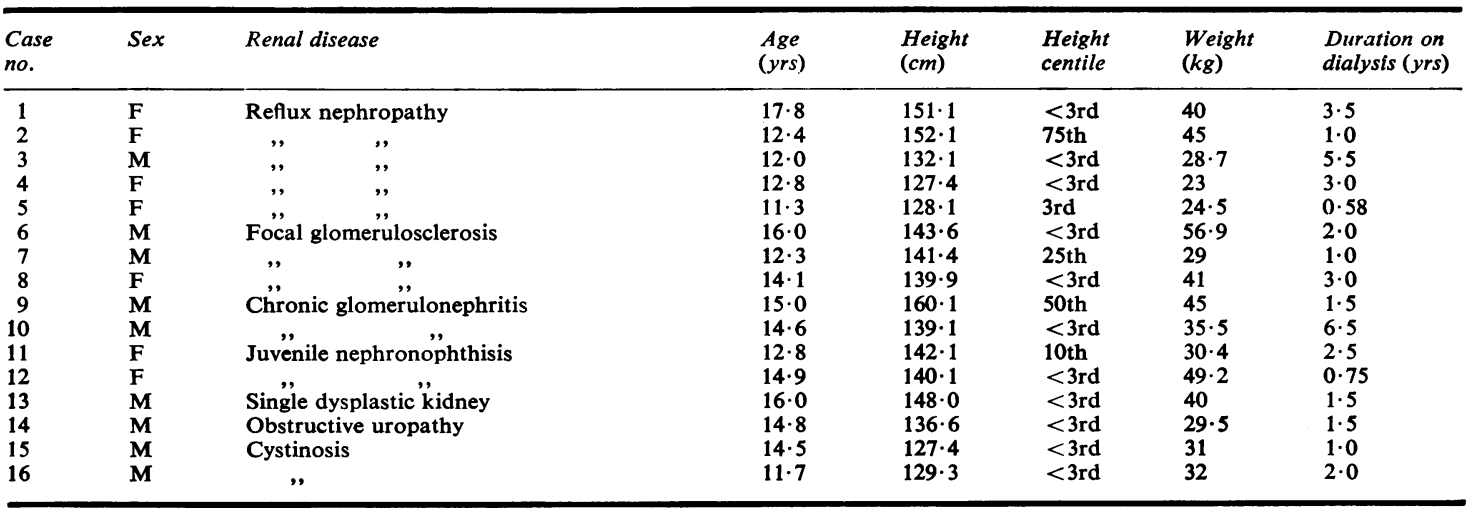

Table 2 Biochemical results in patients and controls (mean $\pm 1 S D)$

\begin{tabular}{|c|c|c|c|c|c|c|c|}
\hline & $n$ & $\begin{array}{l}T G \\
(\mathrm{mmol} / \mathrm{l})\end{array}$ & $\begin{array}{l}\text { Cholesterol } \\
\text { (mmolll) }\end{array}$ & $\begin{array}{l}I R I \\
(m U / l)\end{array}$ & $\begin{array}{l}\text { Blood glucose } \\
\text { (mmol/l) }\end{array}$ & $\begin{array}{l}\text { Plasma albumin } \\
(\mathrm{g} / \mathrm{l})\end{array}$ & $\begin{array}{l}\text { Plasma } \\
\text { transferrin } \\
(g / l)\end{array}$ \\
\hline $\begin{array}{l}\text { Patients } \\
\text { Controls } \\
\text { Significance of difference, } \mathbf{P}\end{array}$ & $\begin{array}{l}16 \\
18\end{array}$ & $\begin{array}{l}1.974 \pm 0.92 \\
0.838 \pm 0.25 \\
<0.001\end{array}$ & $\begin{array}{l}6 \cdot 27 \pm 1 \cdot 27 \\
4 \cdot 49 \pm 0 \cdot 82 \\
<0 \cdot 001\end{array}$ & $\begin{array}{l}20 \cdot 7 \pm 8 \cdot 7 \\
8 \cdot 4 \pm 5 \cdot 2 \\
<0 \cdot 001\end{array}$ & $\begin{array}{l}5 \cdot 07 \pm 0 \cdot 38 \\
4 \cdot 28 \pm 0 \cdot 54 \\
<0 \cdot 001\end{array}$ & $\begin{array}{l}42 \pm 4 \cdot 8 \\
43 \pm 1 \cdot 9 \\
\text { NS }\end{array}$ & $\begin{array}{l}2 \cdot 41 \pm 0.91 \\
2 \cdot 46 \pm 0.52 \\
\text { NS }\end{array}$ \\
\hline
\end{tabular}

TG=triglycerides; IRI = immunoreactive insulin.

Conversion: SI to traditional units-Triglyceride: $1 \mathrm{mmol} / 1 \approx 80.5 \mathrm{mg} / 100 \mathrm{ml}$. Cholesterol: $1 \mathrm{mmol} / 1 \approx 38.6 \mathrm{mg} / 100 \mathrm{ml}$. Blood glucose:

$1 \mathrm{mmol} / 1 \approx 18 \mathrm{mg} / 100 \mathrm{ml}$. 


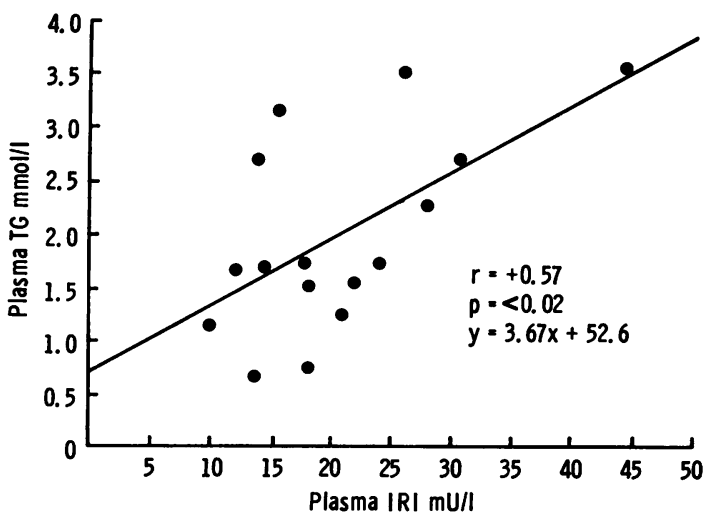

Fig. 1 Plasma triglyceride (TG) concentrations related to plasma immunoreactive insulin (IRI) levels in 16 children on regular haemodialysis.

and transferrin concentrations, as indices of nutritional state, were similar in patients and controls and did not correlate with plasma lipid levels.

Effect of diet. The dietary intakes of total energy, carbohydrates, total fat and proteins expressed as $\%$ RI for the height-age are presented in Table 3. The relationship between the dietary intakes and plasma TG and cholesterol concentrations in the patients is shown in Table 4. There was a tendency for those children with lower intakes of total energy, fats, and proteins to have higher TG levels but TG and carbohydrate intake were poorly correlated. However, when expressed as a percentage of the total energy intake, there was significant positive correlation between plasma TG concentration and percentage of calories derived from carbohydrate (Fig. 2). No correlation between plasma cholesterol concentration and food intakes could be shown.

\section{Discussion}

Raised plasma triglycerides have been commonly reported in adults on regular haemodialysis (Bagdade et al., 1968; Gutman et al., 1973) and recently Pennisi et al. (1976) and Broyer et al. (1976) reported raised TG levels in children on dialysis. Our group of children showed a similar phenomenon. Type IV hyperlipoproteinaemia is commonly found and the majority of our patients exhibited this pattern. Raised TG levels in uraemia are considered to be due to both increased hepatic TG production (Bagdade et al., 1968; Cramp et al., 1976) and decreased TG clearance from plasma (Cattran et al., 1976; Murase et al., 1975). Our finding of high basal plasma insulin levels in the face of raised fasting blood glucose is indicative of glucose intolerance. The positive

Table 3 Diets of children on dialysis

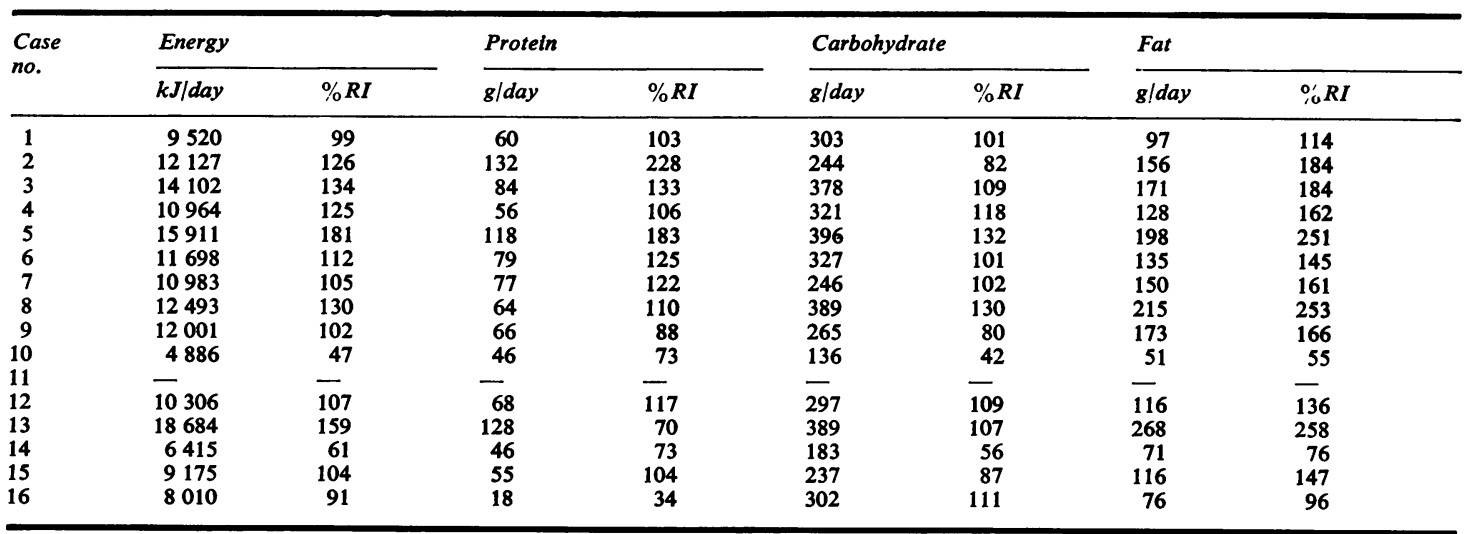

$\% \mathbf{R I}=$ percentage of recommended intake.

Conversion: $S I$ to traditional units-Energy: $1 \mathrm{~kJ} \approx 0.239 \mathrm{kcal}$.

Table 4 Relationship between diet (as \% of RI for height-age) and plasma lipid concentrations

\begin{tabular}{|c|c|c|c|c|c|c|c|c|}
\hline & \multicolumn{2}{|c|}{ Total energy } & \multicolumn{2}{|l|}{ Fat } & \multicolumn{2}{|c|}{ Carbohydrate } & \multicolumn{2}{|l|}{ Protein } \\
\hline & $\boldsymbol{r}$ & $P$ & $r$ & $P$ & $r$ & $P$ & $r$ & $P$ \\
\hline $\begin{array}{l}\text { Triglycerides } \\
\text { Cholesterol }\end{array}$ & $\begin{array}{l}-0.37 \\
-0.13\end{array}$ & $\begin{array}{l}\text { NS } \\
\text { NS }\end{array}$ & $\begin{array}{l}-0.46 \\
-0.06\end{array}$ & $\begin{array}{l}<0 \cdot 1 \\
\mathrm{NS}\end{array}$ & $\begin{array}{l}-0 \cdot 12 \\
-0 \cdot 18\end{array}$ & $\begin{array}{l}\text { NS } \\
\text { NS }\end{array}$ & $\begin{array}{r}-0.38 \\
+0.13\end{array}$ & $\begin{array}{l}\text { NS } \\
\text { NS }\end{array}$ \\
\hline
\end{tabular}




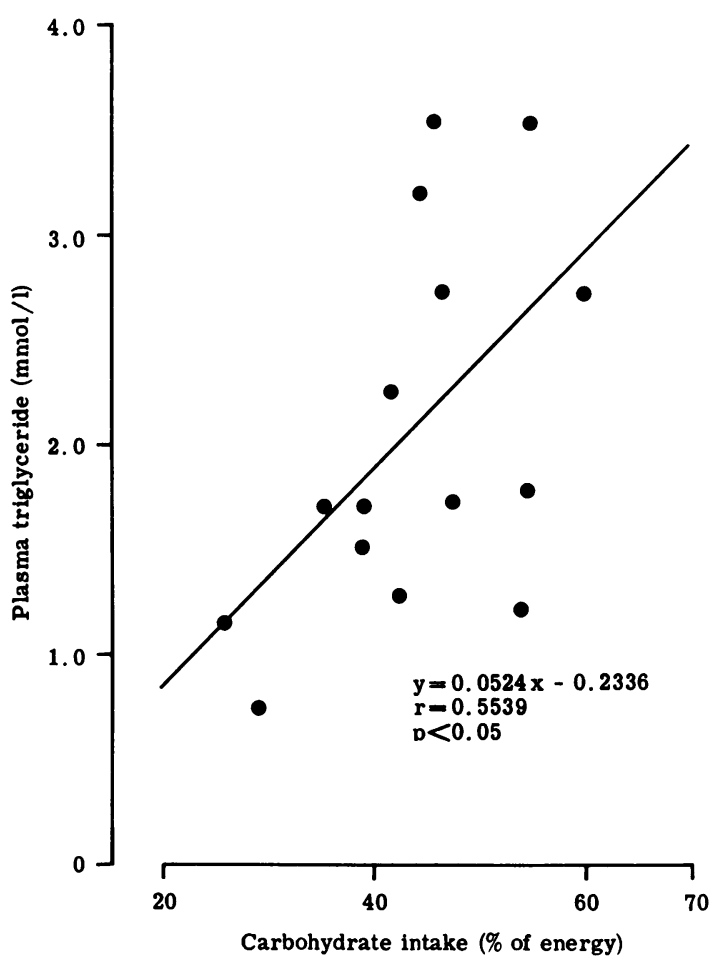

Fig. 2 Plasma triglyceride concentrations related to carbohydrate intake (\% of total energy intake) in 15 children on regular haemodialysis.

correlation shown between plasma insulin and TG concentration is similar to that found in uraemic adults (Bagdade, 1970) and it is possible that hyperinsulinaemia might stimulate an increased hepatic TG production, as suggested for nonuraemic subjects (Reaven et al., 1967; Olefsky et al., 1974).

The role of diet in the pathogenesis of hypertriglyceridaemia in uraemia is not clear. No correlation existed between total energy intake and TG concentration, though higher total energy and protein intakes tended to be associated with lower levels. The TG levels reported here are about $65 \%$ lower than those reported by Broyer et al. (1976) in children on dialysis, and energy and protein intakes in our children were considerably greater than in their study. However, other differences exist in the management of these children, for instance our children dialyse for about $\mathbf{3 0}$ hours a week compared with 16 hours a week. The proportion of total energy intake derived from carbohydrate correlated significantly with TG concentrations. Both Pennisi et al. (1976) and Broyer et al. (1976) showed a similar reiationship between dietary carbohydrate and plasma TG concentration. More recently, Sanfelippo et al. (1977) reported a reduction in plasma TG levels by feeding diet low in carbohydrate and high in polyunsaturated fat. Unfortunately it is not known from their study which of the two variables in the diet altered the TG levels.

Plasma cholesterol concentrations are usually found to be normal in uraemic adults whereas our patients showed considerable increases both compared with controls and with the children reported by Broyer $e$ t al. (1976), though 6 of 17 children in the latter study also showed significantly increased levels. We were unable to show any relationship between diet and plasma cholesterol, though Broyer et al. suggested a relationship with lipid intake. As our patients were taking energy supplements based on food high in saturated fats, it is possible that manipulation of the diet by increasing the polyunsaturated fat intake might lead to a fall in plasma cholesterol, and we are attempting this at present.

The finding of hyperlipidaemia in children on regular haemodialysis awaiting transplantation is disturbing in view of the relationship between hyperlipidaemia and arterial disease shown in prospective studies of normal populations (Kannel et al., 1971; Carlson and Böttiger, 1972) and the increased incidence of premature atherosclerosis and cardiovascular disease reported in adult patients on longterm haemodialysis (Lowrie et al., 1973; Lindner et al., 1974; Bagdade, 1975). Pennisi et al. (1976) studied the morphology of coronary arteries in children who died while on regular haemodialysis for renal failure. In comparison with children dying of other diseases at a similar age, there were changes suggestive of fat deposition in the arterial walls.

While the exact mechanism of the hyperlipidaemia remains obscure, it obviously is important to measure TG and cholesterol concentration both in children on haemodialysis and in children with chronic renal insufficiency who have not yet required dialysis or transplantation. If raised levels are found, attempts can be made to lower them by dietary manipulation or increased dialysis. The need to ensure adequate nutrition in children in renal failure has been emphasized (Chantler and Holliday, 1973). Further studies of the effect of various dietary constituents on plasma lipids are required, but in the meantime it seems reasonable to try to ensure an adequate intake of total energy and protein. Regular diet surveillance is important and for those children with raised lipid levels the proportion of carbohydrate and saturated fat in the diet may need to be controlled.

\section{References}

Bagdade, J. D. (1970). Uremic lipemia. An unrecognized abnormality in triglyceride production and removal. Archives of Internal Medicine, 126, 875-881. 
Bagdade, J. D. (1975). Atherosclerosis in patients undergoing maintenance hemodialysis. Kidney International, 7, Suppl. 3, 370-372.

Bagdade, J. D., Porte, D., and Bierman, E. L. (1968). Hypertriglyceridemia: a metabolic consequence of chronic renal failure. New England Journal of Medicine, 279, 181-185.

Broyer, M., Tete, M. J., Laudat, M. H., and Dartois, A. M. (1976). Plasma lipid abnormalities on chronic haemodialysis: relationship to dietary intake. Proceedings of the European Dialysis and Transplant Association, 14, 385.

Carlson, L. A., and Böttiger, L. E. (1972). Ischaemic heart disease in relation to fasting values of plasma triglycerides and cholesterol. Stockholm prospective study. Lancet, 1 , 865-868.

Cattran, D. C., Fenton, S. S. A., Wilson, D. R., and Steiner, G. (1976). Defective triglyceride removal in lipemia associated with peritoneal dialysis and hemodialysis. Annals of Internal Medicine, 85, 29-33.

Chantler, C., and Holliday, M. A. (1973). Growth in children with renal disease with particular reference to the effects of calorie malnutrition: a review. Clinical Nephrology, 1, 230-242.

Cramp, D. G., and Robertson, G. (1968). The fluorometric assay of triglyceride by a semi-automated method. Analytical Biochemistry, 25, 246-251.

Cramp, D. G., Beale, D. J., Moorhead, J. F., Tickner, T. R., and Wills, M. R. (1976). Triglyceride turnover in chronic renal failure. (Abst.) Clinical Science and Molecular Medicine, 50, $8 \mathrm{P}$.

Department of Health and Social Security (1969). Recommended Intakes of Nutrients for the United Kingdom. Reports on Public Health and Medical Subjects No. 120. HMSO, London.

Gutman, R. A., Uy, A., Shalhoub, R. J., Wade, A. D., O'Connell, J. M. B., and Recant, L. (1973). Hypertriglyceridemia in chronic non-nephrotic renal failure. American Journal of Clinical Nutrition, 26, 165-172.

Ibels, L. S., Simons, L. A., King, J. O., Williams, P. F., Neale, F. C., and Stewart, J. H. (1975). Studies on the nature and causes of hyperlipidaemia in uraemia, maintenance dialysis and renal transplantation. Quarterly Journal of Medicine, 44, 601-614.

Kannel, W. B., Castelli, W. P., Gordon, T., and McNamara,
P. M. (1971). Serum cholesterol, lipoproteins, and the risk of coronary heart disease. The Framingham study. Annals of Internal Medicine, 74, 1-12.

Levine, J., and Zak, B. (1964). Automated determination of serum total cholesterol. Clinica Chimica Acta, 10, 381384.

Lindner, A., Charra, B., Sherrard, D. J., and Scribner, B. H. (1974). Accelerated atherosclerosis in prolonged maintenance hemodialysis. New England Journal of Medicine, 290, 697-701.

Lowrie, E. G., Lazarus, J. M., Mocelin, A. J., Balley, G. L., Hampers, C. L., Wilson, R. E., and Merrill, J. P. (1973). Survival of patients undergoing chronic hemodialysis and renal transplantation. New England Journal of Medicine. 288, 863-867.

McCance, R. A., and Widdowson, E. M. (1969). The Composition of Foods. Special Report Series No. 297. HMSO, London.

Morgan, C. R., and Lazarow, A. (1963). Immunoassay of insulin: two antibody system. Plasma insulin levels of normals, subdiabetic and diabetic rats. Diabetes, 12 , 115-126.

Murase, T., Cattran, D. C., Rubenstein, B., and Steiner, G. (1975). Inhibition of lipoprotein lipase by uremic plasma, a possible cause of hypertriglyceridemia. Metabolism, 24, 1279-1286.

Olefsky, J. M., Farquhar, J. W., and Reaven, G. M. (1974). Reappraisal of the role of insulin in hypertriglyceridemia. American Journal of Medicine, 57, 551-560.

Pennisi, A. J., Heuser, E. T., Mickey, M. R., Lipsey, A., Malekzadeh, M., and Fine, R. N. (1976). Hyperlipidemia in pediatric haemodialysis and renal transplant patients. American Journal of Diseases of Children, 130, 957-961.

Reaven, G. M., Lerner, R. L., Stern, M. P., and Farquhar, J. W. (1967). Role of insulin in endogenous hypertriglyceridemia. Journal of Clinical Investigation, 46, 17561767.

Sanfelippo, M. L., Swenson, R. S., and Reaven, G. M. (1977). Reduction of plasma triglycerides by diet in subjects with chronic renal failure. Kidney International, 11, 54-61.

Correspondence to Dr. M. El-Bishti, Paediatric Department, Guy's Hospital, London SE1 9RT. 